\title{
THE ROLE OF OXIDES IN OXIDATION OF ALLYL ALCOHOL AN D ITS ESTERS
}

\author{
Eugeniy Fedevych ${ }^{1}$, Oleh Datsko², Oleh Fedevych ${ }^{3, *}$
}

https://doi.org/10.23939/chcht13.01.046

\begin{abstract}
The assumption that oxides (glycidol, glycidol acetate, glycidol formate) are the intermediate molecular products of the oxidation reaction of allyl alcohol and its esters in the medium of acetic acid has been grounded. To optimize the process of obtaining glycerin esters the kinetics of these oxides reaction with acetic and formic acids has been investigated. Glycidol formate was found to be the most stable compound and glycidol - the least stable one. The rate of oxides reaction with formic acid is by order higher than that with acetic acid. It is reasonable to use allyl formate as the starting material to achieve the maximum yields of glycerin esters.
\end{abstract}

Keywords: glycerin, allyl acetate, allyl formate, allyl alcohol, oxides.

\section{Introduction}

One of the most effective methods of obtaining high purity glycerin (large-tonnage product which is widely used) is its esters hydrolysis with acetic acid glycerin acetins [1-3], which are synthesized via allyl acetate oxidation [4-5]. On an industrial scale allyl acetate is obtained via oxidative acylation of propylene [6-8].

Acetins are semi-products to obtain glycerin and are singly used as surface active compounds, antistatic and antibacterial agents, and lubricating materials [9]. Triacetin is the most widely used product [10]. It is applied as food additive (E1518), flavoring solvent, and humidifier, as a component while preparing liqueurs and pharmaceuticals, and may be used as a plasticizer and solvent. It also has anti-knock properties and improves

\footnotetext{
${ }^{1}$ Lviv National Agrarian University,

1, V.Velykogo St., 80381 Dubliany, Lviv region, Ukraine

${ }^{2}$ Bogomolets Institute of Physiology,

Laboratory of Experimental Balneology,

Truskavets, Ukraine

${ }^{3}$ Lviv Polytechnic National University,

12, S.Bandery St., 79013 Lviv, Ukraine

*foe69@ukr.net

(C) Fedevych E., Datsko O., Fedevych O., 2019
}

viscosity of biodiesel. It is a component of propellant [8] and possible power source during space flights [9]. Triacetin is used for the production of food plastics as well as acrylic fabric filters for cigarettes due to its ability to absorb carcinogenic substances. Since triacetin is fermentation-resistant, it extends the shelf life of the products and may be a component of confectioneries, including chocolate. Glycerin mono- and diacetin have similar properties [8].

Taking into account the intense interest to the above-mentioned compounds, we studied previously the oxidative acylation of allyl acetate (AAc), allyl alcohol (AAl) and allyl formate (AF) and determined the composition of the resulting products [11]. We also proposed the possible scheme of main and byproducts formation [4]. According to the scheme the oxides are primary intermediate products (glycidol - AAl oxide; glycidol acetate - AA oxide; glycidol formate - AF oxide). They are formed mainly via $\beta$-peroxy radicals [11]. Due to $\sigma-\pi$ conjugation $\mathrm{C}-\mathrm{H}$ bond in $\alpha$-position relative to the double bond is weak and at thermal initiation in the presence of oxygen allyl radical is formed (Eq. (1)). Its transformation leads to the formation of $\beta$-peroxy radicals (Eq. (2)).

$$
\begin{aligned}
& 2 \mathrm{CH}_{2}=\mathrm{CH}-\mathrm{CH}_{2}-\mathrm{OR}+\mathrm{O}_{2} \rightarrow 2 \mathrm{CH}_{2}=\mathrm{CH}-\dot{\mathrm{C}} \mathrm{H}-\mathrm{OR}+\mathrm{H}_{2} \mathrm{O}_{2} \\
& \qquad \begin{array}{l}
\mathrm{R}=-\mathrm{H}, \quad-\mathrm{CH}_{2} \\
\text { where }
\end{array} \\
& \mathrm{CH}_{3}-\dot{\mathrm{C}} \mathrm{H}-\mathrm{OR}+\mathrm{O}_{2} \rightarrow \mathrm{CH}_{2}=\mathrm{CH}-\underset{\mathrm{O}-\dot{\mathrm{O}}}{\mathrm{CH}-\mathrm{OR}}
\end{aligned}
$$
Scheme.

Further transformations may be represented by the

The selectivity of glycerin esters formation is determined by the ratio of the reaction rates $W_{1}, W_{2}$ and $W_{3}$.

So, the aim of this work is the investigation of the kinetics of $\mathrm{AAc}, \mathrm{AAl}$ and $\mathrm{AF}$ oxides consumption under the conditions similar to those of oxidative acylation to confirm the validity of proposed scheme and substantiate the choice of the process optimal conditions. 


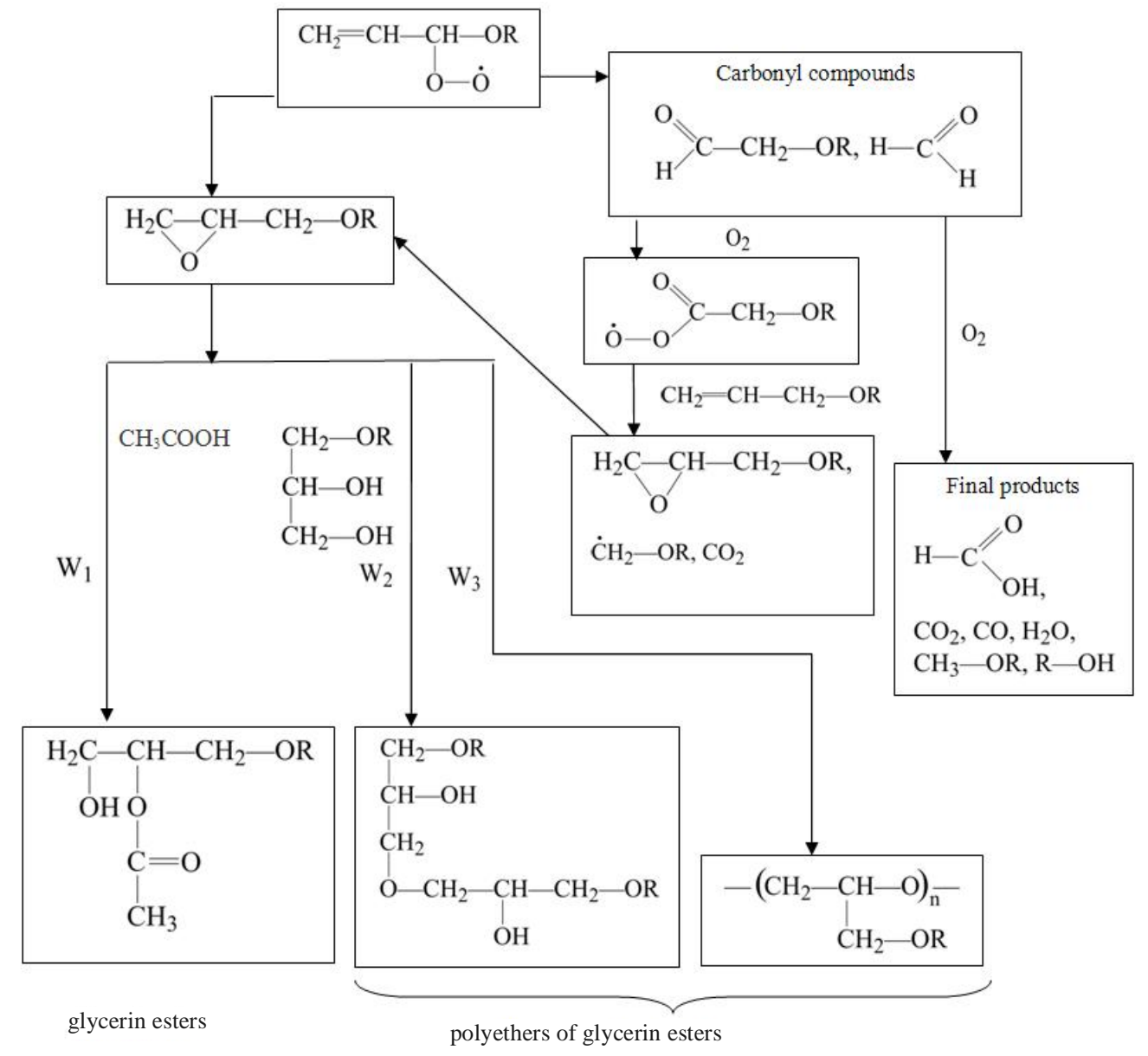

Scheme

\section{Experimental}

To conduct the research, we used:

- Allyl alcohol of PA grade; after three-time rectification a fraction with boiling point of $369-370 \mathrm{~K}$ was selected;

- Allyl acetate was synthesized using a mixture of AAc:acetic anhydride with the molar ratio of $1: 1.1$. The mixture was gradually heated to $353 \mathrm{~K}$ and boiled for one hour using backflow condenser; then it was cooled and neutralized with small portions of $15 \%$ alkaline solution in a dividing funnel, which was cooled with running water. The mixture was segregated. The bottom part was poured out and the top layer was washed with alkaline solution to a neutral reaction. The ether layer was dried over $\mathrm{CaCl}_{2}$ and distilled several times in a stream of argon. A fraction with boiling point of 376-377 K was selected.

- Allyl formate was synthesized using allyl alcohol and distilled formic acid of PA grade. A flask with backflow condenser was loaded with $\mathrm{AAl}$ and threefold excess of formic acid. The mixture was boiled for one hour, distilled with reflux and a fraction up to $368 \mathrm{~K}$ was selected. It was washed several times with $10 \%$ alkaline solution. The ether layer was dried over $\mathrm{CaCl}_{2}$, distilled several times, and a fraction with boiling point of $369 \mathrm{~K}$ was selected.

- Glycidol was obtained by its distillation under reduced pressure. A fraction with boiling point of 338$339 \mathrm{~K}$ at $0.34 \mathrm{kPa}$ was selected.

- Allyl acetate oxide was synthesized using epichlorohydrin and potassium acetate. Distilled epichlorohydrin and dried potassium acetate were boiled in a flask with a stirrer and backflow condenser for $24 \mathrm{~h}$. Then the samples were withdrawn for chromatographic analysis on a column filled with polysorbate-1. Appearance of a new peak, which retention time was longer than that of epichlorohydrin but less than glycerin, was monitored. The temperature of the cube increased by $10 \mathrm{~K}$. The mixture was distilled, and the fraction distilled immediately after epichlorohydrin $(358-363 \mathrm{~K}$ at $5 \mathrm{kPa})$ was selected. After that, the epichlorohydrin was returned to the mixture and the reaction continued for another $20 \mathrm{~h}$. After threefold repetition of the synthesis, the selected 
fractions were redistilled and the product with boiling point of $360-365 \mathrm{~K}$ at $4.8 \mathrm{kPa}$ was selected. According to the chromatographic analysis allyl acetate oxide was of 97\% purity. The result was confirmed by PMR.

- Allyl formate oxide was synthesized according to the similar procedure using epichlorohydrin and potassium formate. A product of $98 \%$ purity with boiling point of $426 \mathrm{~K}$ was obtained.

The oxidation of AAl, AAc and AF by air oxygen in the medium of acetic acid was investigated in a gasphase flow reactor with a volume of $70 \mathrm{~cm}^{3}$, made of stainless steel with electric heating. The air was fed into the reactor by a capillary and mixing was done by bubbling. The vapors removed with air were condensed in a backflow condenser cooled by a refrigerant with a corresponding temperature. The accuracy of the temperature control in the reactor was $\pm 1 \%$.

The kinetics of AAc, AAl and AF oxides consumption in the medium of acetic and mixture of acetic and formic acids was studied in a glass reactor with a volume of $10 \mathrm{~cm}^{3}$ equipped with a thermosetting casing, a backflow condenser and a capillary sampler.

The analysis of liquid products relative to the content of water, formic and acetic acids, $\mathrm{AAc}, \mathrm{AAl}, \mathrm{AF}$, and glycerin esters was carried out with Color-100 chromatograph with a catharometer using a chromatographic column $(l=2 \mathrm{~m})$ filled with polysorb-1 (grain size was $0.15-0.25 \mathrm{~mm}$ ). Gas-carrier (He) consumption was $2.5 \mathrm{l} / \mathrm{h}$. The column was placed in a thermostat with the temperature programming from 423 to $543 \mathrm{~K}$; heating rate was $16 \mathrm{~K} / \mathrm{min}$.

The content of by-products during oxidation of $\mathrm{AAc}, \mathrm{AAl}$ and $\mathrm{AF}$ was determined on a column with $l=1.5 \mathrm{~m}$ filled with chromatin NA-W with applied liquid phase (dinonyl phthalate, $5 \%$ by weight of carrier) using a flame-ionisation sensor. The temperature of the thermostat column was programmed from 323 to $423 \mathrm{~K}$ at the heating rate of $3 \mathrm{~K} / \mathrm{min}$. The relative error did not exceed $5 \%$.

Experimentally obtained kinetic dependences $C_{i}=f(\tau)$ were approximated by the orthogonal Chebyshev polynomial, and a kinetic curve in an analytic form was received. Using the differentiation of this polynomial an analytical dependence of the reaction rates $(W, \mathrm{~mol} / \mathrm{l} \cdot \mathrm{s})$ on time $(\tau, \mathrm{s})$ was obtained.

$$
W=\varphi(\tau), \text { where } \varphi(\tau)=f^{\prime}(\tau)
$$

\section{Results and Discussion}

The kinetics of oxides consumption in the medium of acetic and a mixture of acetic and formic acids is represented in Fig. 1. Since the consumption rate of oxides is much higher than the formation rates during AAl or its esters oxidation, the experiments were carried out at $344 \mathrm{~K}$, i.e. at the temperature much lower than the temperature of oxidation acylation process.

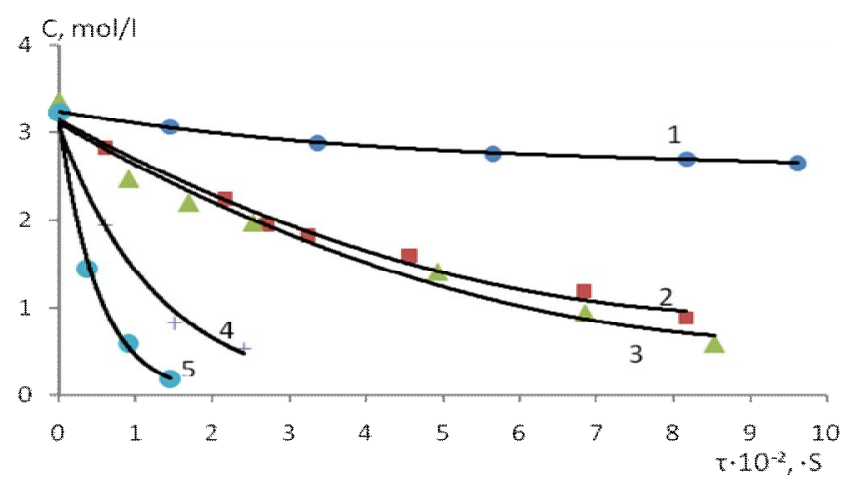

Fig. 1. Kinetic curves of $\operatorname{AAc}(2,5), \operatorname{AAl}(3)$ and $\operatorname{AF}(1,4)$ oxides consumption in the medium of acetic (1-3) and a mixture of acetic and formic acids with molar ratio of $3: 1(4,5)$

We can see from Fig. 1 that the consumption rate of AF oxide is about 5 times less than those of AAc or $\mathrm{AAl}$ oxides. That is why, when oxidizing AAl, AAc and $\mathrm{AF}$ in inert solvents, the highest kinetic equilibrium concentration of oxide is observed for AF [4].

Within the initial period the reaction products are glycerin esters - the products of acetic acid (AA) and formic acid (FA) addition to the oxide (monoacetate, diacetate, monoacetate formate). Then the esterification of free $\mathrm{OH}$ groups takes place. The selectivity of glycerin esters formation relative to the spent oxide is $98 \%$ for glycidolamyate, $92 \%$ for glycidolacetate and $90 \%$ for glycidol.

The analysis of the dependence of the consumption rates of $\mathrm{AAc}, \mathrm{AAl}$ and $\mathrm{AF}$ oxides and the accumulation of the corresponding glycerin esters on the oxides concentration during the reaction is important (Fig. 2). At the beginning of the reaction, when $C_{A A}=3.3 \mathrm{~mol} / \mathrm{l}$, the rate of oxide consumption (curve 1) is much greater than the rate of glycerin esters accumulation (curve 2). However, during reaction proceeding, these rates are gradually aligned. The difference between curves 1 and 2 is the rate of glycerin ethers and polyethers formation. Its highest value is observed at the beginning, and then it gradually decreases to zero. This dependence of glycerin ethers formation rate indicates that they are predominantly formed by polymerization of oxides in the given conditions. If they were formed by joining free alcohol groups to the oxide, then the difference between curves 1 and 2 (Fig. 2) would be observed during the reaction. The increase in selectivity of oxides conversion into esters to the end of the reaction contradicts this. In the case of glycidol formate, glycerin polyethers are almost not formed and the rate curves of oxide consumption and accumulation of glycerin esters practically coincide. 
The peculiarity of oxide consumption in AA is that the rate of their consumption tends to zero, although the solution still has a certain residual concentration of oxide. We can assume that the oxide consumption is inhibited by reaction products - glycerin esters due to increased viscosity of the solution.

It was found $[4,11]$ that a large amount of FA is formed as a by-product of the reaction. Therefore, it was advisable to study its effect on the consumption of AAc, $\mathrm{AAl}$ and AF oxides. The results are presented in Fig. 3.

In the presence of $\mathrm{FA}$, the rate of oxide consumption increases by an order of magnitude. In the case of AAl oxide, the reaction proceeds so fast that even when mixing reagents at room temperature a significant amount of heat is released and the oxide is converted into glycerine polyethers.

In the presence of FA (Fig. 3) the difference in curves 1 and 2 is observed during the reaction until the oxide is completely consumed. Obviously, FA not only accelerates the addition of AA to oxide, but also at deep

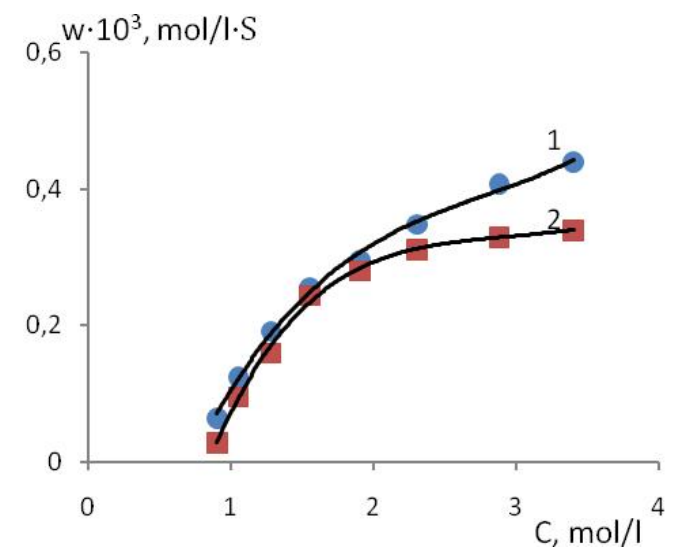

a) stages contributes to the addition of $-\mathrm{OH}$ groups of glycerin esters to the oxide ring to form glycerin polyethers.

In the presence of FA, the selectivity of oxides conversion to glycerin esters slightly decreases; it is 93$95 \%$ for glycidol formates, $76 \%$ for glycidol acetate, and is close to zero for glycidol, since almost all glycidol is consumed for the formation of polymeric products.

Thus, according to the oxides stability in the medium of AA and FA mixture, as well as the selectivity of their conversion into glycerol esters, the oxides can be arranged in a row: glycidol formate $>$ glycidol acetate > glycidol.

The same sequence regarding the maximum accumulation of intermediate oxides and the selectivity of glycerin esters formation is for substrates that are subject to air oxidation $(\mathrm{AF}>\mathrm{AAc}>\mathrm{AAl})$.

As we can see from the Scheme, the rate of glycerin esters accumulation is the difference between the rate of oxide formation and its conversion into glycerin polyethers.

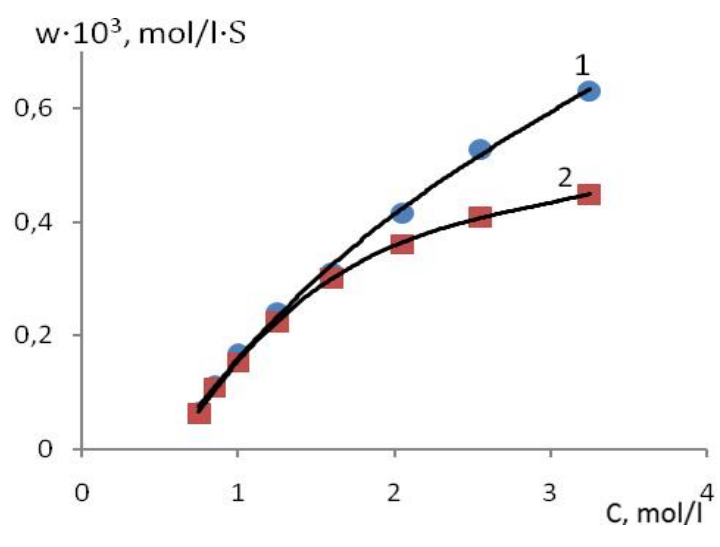

b)

Fig. 2. Rates of AAc (a) and AAl (b) oxides consumption (curves 1) and glycerin esters accumulation (curves 2) vs. oxides concentration during the reaction (AA as a medium; $T=344 \mathrm{~K}$ )

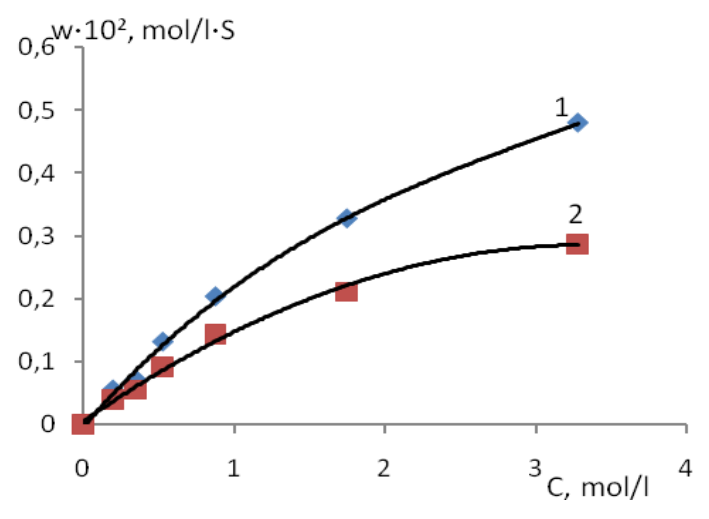

a)

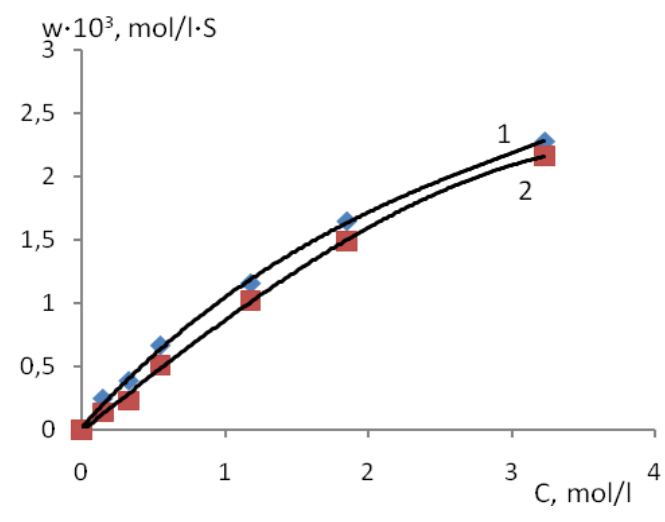

b)

Fig. 3. Rates of AAc (a) and AF (b) oxides consumption (curves 1) and glycerin esters accumulation (curves 2) vs. oxides concentration during the reaction (AA and FA mixture is a medium; $T=344 \mathrm{~K}$ ). For (a) molar ratio FA:AA = 10:4.4; for (b) FA:AA = 1:1 
The obtained results confirm that the oxide is the main intermediate molecular product of $\mathrm{AAc}, \mathrm{AAl}$ and $\mathrm{AF}$ oxidation. Its successive conversion in two parallel directions (the formation of glycerin esters and the formation of glycerin ethers and polyethers) determines the selectivity of glycerin esters formation.

According to the presented scheme, the total rate of oxide consumption in the presence of acetic and formic acids can be expressed by Eq. (3):

$$
W_{o x}=k_{1} \cdot C_{o x} \cdot C_{A A}+k_{2} \cdot C_{o x} \cdot C_{F A}+k_{3} \cdot C_{o x} \cdot C_{F A} \cdot C_{G E}
$$

where $W_{o x}$ - total rate of oxides consumption; $C_{o x}-$ concentration of oxide; $C_{A A}$ - concentration of acetic acid; $C_{F A}$ - concentration of formic acid; $C_{G E}$ - concentration of glycerin esters; $k_{1} \cdot C_{o x} \cdot C_{A A}$ - rate of oxides consumption to form glycerin acetates; $k_{2} \cdot C_{o x} \cdot C_{F A}$ - rate of oxides consumption to form glicerin formates; $k_{3} \cdot C_{o x} \cdot C_{F A} \cdot C_{G E}-$ rate of oxides consumption to form glycerin ethers (polyethers), which is defined as the difference between the total rate of epoxides consumption and the rate of glycerin esters accumulation.
By substituting the values of oxide consumption rate and the corresponding concentrations into Eq. (3), we obtain a system of 6-8 equations, the solution of which by the method of least squares allows us to calculate the values of the rate constants and the kinetic parameters of these reactions (Table 1).

Eq. (3) gives an extreme dependence of the rate of glycerin esters formation on the concentration of the substrate subject to oxidation (Figs. 4 and 5).

Since during oxidation of $\mathrm{AAl}$ and its esters in the medium of AA the kinetically equilibrium concentration of oxides is very low, it can be assumed that the rate of oxides formation $\left(W_{1}\right)$ is equal to the general rate of their consumption $\left(W_{o x}\right)$ :

$$
W_{1}=W_{o x}
$$

The rate of liquid phase oxidation $\left(W_{0}\right)$ is a function of the concentration of an oxidized substance $\left(C_{c}\right)$ and oxygen $\left(C_{\mathrm{O} 2}\right)$.

$$
W_{0}=f\left(C_{c}, C_{O 2}\right)
$$

Kinetic parameters of oxides conversion in the medium of AA and FA

\begin{tabular}{|c|c|c|c|c|}
\hline Oxide & $T, \mathrm{~K}$ & $k_{1} \cdot 10^{4}, 1 / \mathrm{mol} \cdot \mathrm{s}$ & $k_{2} \cdot 10^{4}, 1 / \mathrm{mol} \cdot \mathrm{s}$ & $k_{3} \cdot 10^{4}, 1^{2} / \mathrm{mol}^{2} \cdot \mathrm{s}$ \\
\hline \multirow{4}{*}{ Glycidol } & 344 & $0.13 \pm 0.02$ & $4.0 \pm 1.0$ & $62 \pm 15$ \\
\cline { 2 - 5 } & 359 & $0.28 \pm 0.03$ & $8.9 \pm 1.5$ & $112 \pm 25$ \\
\cline { 2 - 5 } & 374 & $0.65 \pm 0.06$ & $18.0 \pm 3.0$ & $201 \pm 40$ \\
\cline { 2 - 5 } & $E, \mathrm{~J} / \mathrm{mol}$ & 57440 & 53610 & 42130 \\
\cline { 2 - 5 } Glycidol acetate & $k_{0}$ & 6637 & 55335 & 15240 \\
\cline { 2 - 5 } & 344 & $0.14 \pm 0.02$ & $1.5 \pm 0.4$ & $1.00 \pm 0.2$ \\
\cline { 2 - 5 } & 359 & $0.32 \pm 0.04$ & $2.8 \pm 0.5$ & $1.62 \pm 0.3$ \\
\cline { 2 - 5 } & 374 & $0.70 \pm 0.07$ & $6.0 \pm 0.7$ & 37340 \\
\cline { 2 - 5 } & $E, \mathrm{~J} / \mathrm{mol}$ & 55540 & 36320 & 26.5 \\
\hline \multirow{5}{*}{ Glycidol formate } & $k_{0}$ & 3855 & 58.2 & $0.10 \pm 0.03$ \\
\cline { 2 - 5 } & 344 & $0.05 \pm 0.01$ & $1.1 \pm 0.3$ & $0.36 \pm 0.02$ \\
\cline { 2 - 5 } & 359 & $0.09 \pm 0.01$ & $2.2 \pm 0.4$ & 42120 \\
\cline { 2 - 5 } & 374 & $0.16 \pm 0.02$ & $4.5 \pm 0.6$ & 25.4 \\
\cline { 2 - 5 } & $E, \mathrm{~J} / \mathrm{mol}$ & 44040 & 49790 & 3945 \\
\hline
\end{tabular}

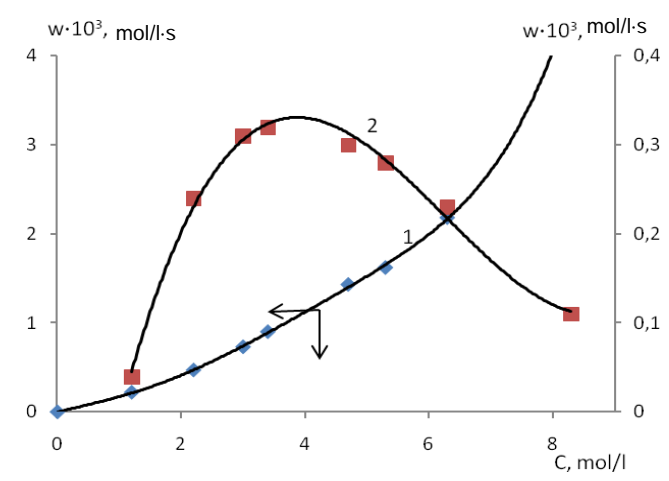

Fig. 4. Rates of allyl acetate oxidative acylation (1) and glycerine esters formation (2) vs. initial concentration of allyl acetate in AA $(T=435 \mathrm{~K}, P=2.94 \mathrm{MPa})$

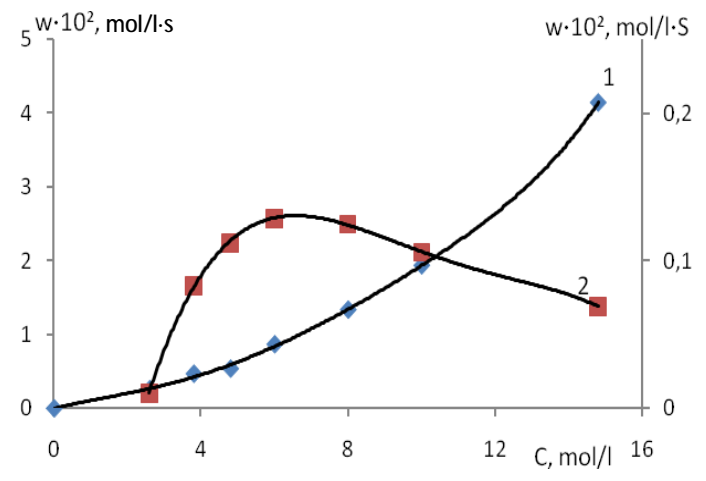

Fig. 5. Rates of allyl alcohol oxidative acylation (1) and glycerine esters formation (2) vs. initial concentration of allyl alcohol in AA $(T=423 \mathrm{~K}, P=2.94 \mathrm{MPa})$ 
So, the rate of oxides formation can be expressed as:

$$
W_{1}=\varphi\left[f\left(C_{c}, C_{O 2}\right)\right]
$$

where $\varphi$ is a transforming function, which under the same conditions depends only on the reaction mechanism; it is the same for the oxidation processes of $\mathrm{AAc}, \mathrm{AAl}$ and $\mathrm{AF}$, which have a similar mechanism.

If the rate of glycerin esters formation $\left(W_{2}\right)$ according to Eq. (3) is equal to

then:

$$
W_{2}=k_{1} \cdot C_{o x} \cdot C_{A A}+k_{2} \cdot C_{o x} \cdot C_{F A},
$$

$$
\begin{gathered}
W_{o x}=W_{2}+k_{3} \cdot C_{o x} \cdot C_{F A} \cdot C_{G E}=W_{1}=\varphi\left[f\left(C_{c}, C_{O 2}\right)\right] \\
W_{2}=\varphi\left[f\left(C_{c}, C_{O 2}\right)\right]-k_{3} \cdot C_{o x} \cdot C_{F A} \cdot C_{G E}
\end{gathered}
$$

Thus, the rate of glycerin esters accumulation is the difference between the rates of oxide formation and its conversion into glycerin ethers and polyethers.

With the increase in the concentration of the substrate subject to oxidation (AAc, AAl, AF) and sufficient oxygen concentration, the rate of oxides formation increases or reaches some limit value. Therefore, the extreme nature of the dependence of glycerin esters formation rate on AAl (Fig. 4) or AAc (Fig. 5) concentration is conditioned by the second constituent of Eq. (8), which includes the oxides consumption for the formation of glycerin polyethers.

\section{Conclusions}

Comparison of the regularities of the oxides consumption under conditions similar to the oxidation of the corresponding hydrocarbons with the oxidation regularities confirms that oxides are intermediate molecular products, which are consumed in two parallel directions under oxidation reaction conditions:

- they react with acetic and formic acids to form the desired reaction products - glycerin esters;

- they are consumed to form glycerin polyethers via direct polymerization (especially at the beginning of the reaction) and as a result of free hydroxyl groups addition to the oxide ring, especially in the presence of formic acid, which accelerates the oxides consumption.

Allyl formate oxide is the most resistant to AA and FA and most selective to form glycerin esters with these acids. Therefore, in order to achieve the highest possible yields of glycerin esters, it is most appropriate to use oxidative acylation of allyl formate, which can be obtained by oxidative formylation of propylene.

\section{References}

[1] Zhyznevskyi V., Fedevych Ye.: Perspektivnye Kataliticheskie Processy Poluchenia Acrylatnykh Monomerov. Svit, Lviv 1991.

[2] Vermeulen N., Delcamp J., White C.: J. Am. Chem. Soc., 2010, 132, 11323. https://doi.org/10.1021/ja104826g

[3] Henderson W., Check C., Proust N., Stambuli J.: Org. Lett, 2010, 12, 824. https://doi.org./ 10.1021/ol902905w

[4] Fedevych Ye.: Zh. Prikl. Khimii, 2002, 38, 668.

[5] Chen K., Zhang P., Wang Y., Li H.: Green Chem., 2014, 16, 2344. http://dx.doi.org/10.1039/C3GC42135J

[6] Diment O., Kazanskyi K., Mironovych A.: Glycol i Druhie Proizvodnye Okisei Etilena i Propylena. Khimia, Moskva 1996.

[7] Uchuskin M., Makarov A., Butin A.: Chem. Heterocycl. Compd., 2014, 50, 791. https://doi.org/10.1007/s10593-014-1534-z

[8] Campbell A., Stahl S.: Acc. Chem. Res., 2012, 45, 851. https://doi.org/10.1021/ar2002045

[9] Janis R., Klasek A., Bobalova J.: J. Food Lipids, 2006, 13, 199. https://doi.org/10.1111/j.1745-4522.2006.00045.x

[10] https://pubchem.ncbi.nlm.nih.gov/compound/triacetin

[11] Fedevych Ye., Datsko O., Fedevych O.: XV Naukova Conf.

"Lvivski Khim. Chytannia". Ukraine, Lviv 2015, F8.

Received: May 12, 2017 / Revised: May 06, 2018 / Accepted: June 24, 2018

\section{ОКСИДИ ЯК ПРОМІЖНІ ПРОДУКТИ РЕАКЦІї ОКИСНЕННЯ АЛІЛОВОГО СПИРТУ ТА ЙОГО ЕСТЕРІВ КИСНЕМ ПОВІТРЯ В СЕРЕДОВИЩІ ОЦТОВОЇ КИСЛОТИ}

Анотація. Обгрунтовано допущення, що проміжним молекулярним продуктом реакиї окиснення алілового спирту та його естерів у середовищі оцтової кислоти є оксиди

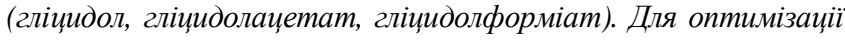
процесу одержання естерів глічерину досліджено кінетику взаємодї цих оксидів з очтовою та мурашиними кислотами. Встановлено, щзо найстійкішим є глічидолформіат, а найменш стійким - глічидол. 3 мурашиною кислотою взаємодія оксидів проходить на порядок швидие ніж оцтовою. В присутності мурашиної кислоти селективність різко зменшується. Для досягнення максимального виходу естерів гліцерину як вихідний продукт дочільно використовувати алілформіат.

Ключові слова: гліцерин, алілачетат, алілформіат, спирт аліловий, оксиди. 